\title{
Combination of the Technological Innovation and Innovation of the Business Model
}

\author{
Liu Limei \\ Heilongjiang Agricultural Engineering \\ Vocational college \\ Harbin, \\ houyanming \\ Heilongjiang Agricultural Engineering \\ Vocational college \\ Harbin,
}

\author{
xubing \\ Heilongjiang Agricultural Engineering \\ Vocational college \\ Harbin,
}

\begin{abstract}
The main part of the industrial innovation is the firms. Firms are also the powerful source of the innovative impetus. The combination of technological innovation and innovation of the business model is an effective way to help firms improve competitiveness and the realization mechanism of the industrial innovation. Now with the increasingly market competition, the simple pursuit of technological innovation or business model innovation has been unable to make enterprises to maintain long-term competitive advantage. Only combine the technical innovation and the business model innovation to form a complete value chain can help the enterprises to be invincible. This article analyzes the mechanism of the combination of technological innovation and business model innovation. The article presents the problems of the combination of technological innovation and business model innovation in current China and puts forward corresponding countermeasures and suggestions for the combination.
\end{abstract}

Keywords-industrial innovation, technological innovation, innovation of the business model, Industrial competitiveness

\section{INTRODUCTION}

Industrial transformation and upgrading has become a major economic issue of concern to the whole society in general. Achieving industrial transformation and upgrading can improve capacity of innovation and technical level, change the situation of low products' value-added, overcapacity, lack of high-end products supply and improve the overall quality of the industry. Moreover it can be an important driving force to promote the upgrading of consumption, lead and create new consuming demand and expand consuming market. Achieving industrial transformation and upgrading can improve the efficiency of the use of resource and promote the development of industrial development model ${ }^{[1]}$. It changes into strategies of implement of the innovation from relying on the factor-driven. It can make the industry to be fine, strong and on this basis to be more high-end. It can also break a path of innovation for the Chinese industry in the contradictory situation of the economic restructuring and economic transformation and upgrading $^{[2]}$.

The continually transformation and upgrade is the objective laws of the industrialization process. Development of the industry cannot live without technological innovation in even one day. In the "Industrial revolution", industry, particularly the manufacturing industry is the carrier of the majority of the technological innovation ${ }^{[3]}$. Industrial technology innovations can support economic prosperity and the stop of the technological innovations means the crisis. The same with all the countries in the world, China's industrialization and modernization have always been in the constantly upgrade process of the industrial structure, technology and institutional mechanisms. Since the reform and opening up of China, Chinese industry helps many enterprises to achieve technological progress and China become the world's largest industrial producer through the "imitative innovation" or the "innovative imitation" during the process of accelerating industrialization. In the new situation, Chinese industry has faced tremendous pressure from the transformation and upgrading. Moreover, the industrial transformation and upgrading must rely more on the innovation, even the imitation, learn 
and introduction also rely on the innovation. In conclusion the originality and the differentiation are all necessary ${ }^{[4]}$.

Industrial innovation, especially industrial technology innovation must combine with the practice business model innovation and should form the institutional environment which contributing to enterprises combining the technological innovation and business model innovation. If the government departments instead of enterprises to make decisions of industrial transformation and upgrading too confidently, it will be difficult to get great results of industrial transformation and upgrading and even pay the costs of unreasonable decisions. For example, the substantial investment (repeated investment in many cities) forms the excess capacity over the market capacity, the benefits will become lower resulting from immature technology and policy support some blind expansion large project will have adverse consequences. Development of photovoltaic industry, new energy industry, environmental industry and other strategic emerging industries requires effective institutional arrangements. ${ }^{[5]}$ Only based on the confidence of business investment, industrial innovation is able to be a kind of sustainable and efficient activity and the motivation of sustained economic growth and promote industrial development ${ }^{[6]}$.

\section{AT THE PRESENT STAGE, THE ISSUES OF ORGANIC COMBINATION OF TECHNICAL \\ INNOVATION AND BUSINESS MODEL INNOVATION}

\section{A. Lack of consciousness of innovation transformation and concept behind}

Technological innovation is an organic whole consists of technology development and utilization. In this whole, it is not only need to consider the possibility of technological development based on technological development law from the technical point of view, but also need consider the effectiveness of technology development from the market-oriented view. Market leading the direction of technology development and the law of development of the technology itself determine the extent of the status and extent of achievement. Three factors together form a complete process of technological innovation. They are technology development, transfer of outcomes of development and effective use of achievements of technology development. In reality, due to industrial enterprises lack of consciousness of transfer innovation, the transformation rate of scientific and technological achievements is low widespread and poor usability and promotion are existence universally. The problems of matching the technological developments and demand of users caused the disjointed situation between the technical progresses and the actual promote the applications.Porter's "value chain" theory shows competition among enterprises is not the competition in the one part, but the competition in the entire value chain. The overall competitiveness of the entire value chain determines the competitiveness of enterprises. However, in the present stage, many Chinese industrial enterprises keep a outdated concept of value chain. They ignore the enormous value of the value chain. Therefore, they cannot attach great importance to the necessity and urgency of the organic combination of the technical innovation and business model innovation. This situation leads to another embarrassing situation which is many results of technological developments are limited to articles and samples and new products have been transformed cannot open markets through effective distribution channels. Innovation of business model

B. Realistic conditions limit the organic combination of technical innovation and business mode innovati

In the enterprises, the outstanding management talents is the source of vitality, is the leader in enterprise innovation power. Apple's success is thanks to the excellent leadership of Steve Jobs, excellent product designers, excellent product marketing staff and Apple's strong corporate culture and institutional that encourages innovation. Only the enterprise keeping a number of outstanding creative talents and innovative corporate culture can achieve the organic combination of technical innovation and business model innovation, and eventually translate it into the core competitiveness of enterprises. Therefore, lacking of high-level management personnel is an important obstacle to enterprises to achieve the organic combination of technical innovation and business model innovation and to enhance the competitiveness.

C. Lacking of high risk prevention mechanism and insufficient funding.

Realize the organic combination of technology innovation and business model innovation, it objective has technology 、 market 、 organization and resource uncertainty aspects, these uncertainties have led to high risk, reality society cannot provide high risk prevention mechanism for innovation, considering the high risk of market ,company should be doubly cautious to make a decision, lacking of innovation initiative. Due to the limitation of funding, the enterprise in the practice of market research and innovation are restricted in a large extent, so company that has less fund cannot achieve organic combination of technology innovation and business model innovation.

D. Lacking of marketing environment and policy supporting system.

The organic combination of technology innovation and business model innovation needs good macrocircumstance. The main power of enterprise innovation is to obtain high profits, innovation is proceeded only when the economic outlook has optimistic expectations, this request stability growth of macroeconomics and good market prospects. Besides, government's policy support is also an important reason to realize the organic combination of technology innovation and business model innovation, nowadays, many government's supporting policies do not reach the designed position, which is not formed a complete innovation policy support system.

\section{MEASURES TO REALIZE ORGANIC COMBINATION OF TECHNOLOGY INNOVATION AND BUSINESS MODEL \\ INNOVATIONLACK OF CONSCIOUSNESS OF INNOVATION TRANSFORMATION AND CONCEPT BEHIND}

In order to promote enterprises to realize the combination of technology innovation and business model innovation, which is to through the establishment of different categories of high-tech park 、 realization of industrial agglomeration a agglomeration of technology and talents, realize the specialization of technology innovation through the high-tech park and agglomeration. 
Through government advocated to realize effective docking enterprise with high and new technology industrial park, in the application of the system to solve the technology, transformation, and the application of established based on the requirement of the user innovation mechanism, at the same time, the government provides policy support to enterprises to achieve business model innovation, technology innovation and adapt to the business model of organic combination, establish a complete smooth value chain, so as to realize the value of appreciation, improve social welfare.

\section{A. Build an improved policy support systemLack of good management talent}

In terms of the government, the scientific research institution construction should be supported, through the establishment of different levels of high-tech park, strive to create effective technology development achievements transfer and enterprises make full use of social atmosphere establishing the important position of enterprises in technological innovation. In addition, the government could regulate the income distribution through reforming of personnel system and personnel policies such as form the social atmosphere of respecting talent, actively for the enterprise, scientific research institutions to cultivate the high quality, high level of creative talents. Due to some companies cannot bear the risk of innovation at the same time, so the government should guarantee the funding of finance, credit and public investment for enterprises to realize the combination of technology innovation and business model innovation.

China's economy is in a transition period, in order to encourage enterprises' innovation, all levels government departments should intensify efforts to increase policy support work. Such as Alibaba which is a business model innovation enterprise, government should give necessary policies in such aspects as legal dispute with the supply of laws and regulations in network infrastructure, as well as the electronic payment, the third party logistics, tax and ecommerce. Which should be seen at the same time, to the financial innovation tool, such as paypal, the Bank of China is lack of necessary financial innovation support service policy, which is shown the policy lag and passivity. With a enhancement of people's innovation consciousness, under the condition of a large number of small and medium-sized innovation enterprises rise, all levels of government departments should be more actively do a good job in service for more innovative enterprises to provide better policy support system and is conducive to the growth of entrepreneurship policy environment, to provide dynamic support for enterprises to realize innovation and environmental protection.

\section{B. Enterprise countermeasures}

From the side of large enterprises, in order to realize the combination of technology innovation and business model innovation, enterprises need to build its own technology development center in high and new science and technology park which is to improve its technology development ability and level and construct the technology development achievements effective use and implement mechanism of the market value. Besides, the large enterprise should play a leading role by creating innovative corporate culture, innovation of the existing business model and realize the combination of technology innovation business model innovation in an effective way. With all these methods, a complete smooth value chain has been formed. From the small businesses, the main thing is to deepen the internal reform of enterprises, set up to undertake technology development efforts and effective use of the mechanism, actively explore the effective commercial mode, trying to be a part of the value chain system.

Realize the technology innovation and business model innovation also requires enterprises to actively implement the strategy of innovative personnel training and reserves, attract and keep excellent human resources, some powerful enterprise should try to cooperate with universities, pay more attention to cultivate and attract a group of professional quality and innovation ability of talents. Meanwhile, companies should strive to improve the senior management personnel of innovation consciousness, crisis consciousness and the concept of value chain, and lay a foundation for the long-term development of the enterprise.

\section{Countermeasures for scientific research institution and university}

Scientific research institutes and universities, which provide technology development achievements, should to enhance the consciousness of the transformation of scientific and technological achievements, intensify market-oriented technology development achievements that can provide useful technology results. Institutes and universities should change from only attach importance to technology development itself from the past to emphasize the technical development of the market success, promote the market orientation of technical development activities, make the results of technological development more possible, avoid the embarrassing situation of technology development achievements is limited to articles and samples, which can make the sustained growth of the economy have more reliable technical guarantee.

In order to realize the combination of technology innovation and business model innovation, enterprise needs to make serious exploration and attempt for a long time. The senior managers of enterprise should have crisis awareness to innovative products market value implementation. It also needs enterprises and universities establish long-term cooperation mechanism to in each link of product value chain and the government's policy support. Organic combination of technology innovation and business model innovation model from the exploration to the successful operation is a dynamic process, in which there are many uncertain factors, but once successful, it can create value and exert energy will make the enterprise benefit, each enterprise in the industry through technical innovation and the combination of business model innovation, will eventually increase the industry innovation ability and competitiveness.

\section{MEASURES TO REALIZE ORGANIC COMBINATION OF TECHNOLOGY INNOVATION AND BUSINESS MODEL INNOVATION}

\section{A. Government countermeasure}

Build an improved policy support system. In terms of the government, the scientific research institution 
construction should be supported, through the establishment of different levels of high-tech park, strive to create effective technology development achievements transfer and enterprises make full use of social atmosphere, establishing the important position of enterprises in technological innovation. In addition, the government could regulate the income distribution through reforming of personnel system and personnel policies such as form the social atmosphere of respecting talent, actively for the enterprise, scientific research institutions to cultivate the high quality, high level of creative talents. Due to some companies cannot bear the risk of innovation at the same time, so the government should guarantee the funding of finance, credit and public investment for enterprises to realize the combination of technology innovation and business model innovation.

China's economy is in a transition period, in order to encourage enterprises' innovation, all levels government departments should intensify efforts to increase policy support work. Such as Alibaba which is a business model innovation enterprise, government should give necessary policies in such aspects as legal dispute with the supply of laws and regulations in network infrastructure, as well as the electronic payment, the third party logistics, tax and e-commerce. Which should be seen at the same time, to the financial innovation tool, such as paypal, the Bank of China is lack of necessary financial innovation support service policy, which is shown the policy lag and passivity. With a enhancement of people's innovation consciousness, under the condition of a large number of small and medium-sized innovation enterprises rise, all levels of government departments should be more actively do a good job in service for more innovative enterprises to provide better policy support system and is conducive to the growth of entrepreneurship policy environment, to provide dynamic support for enterprises to realize innovation and environmental protection.

\section{B. Enterprise countermeasures}

From the side of large enterprises, in order to realize the combination of technology innovation and business model innovation, enterprises need to build its own technology development center in high and new science and technology park which is to improve its technology development ability and level and construct the technology development achievements effective use and implement mechanism of the market value. Besides, the large enterprise should play a leading role by creating innovative corporate culture, innovation of the existing business model and realize the combination of technology innovation business model innovation in an effective way. With all these methods, a complete smooth value chain has been formed. From the small businesses, the main thing is to deepen the internal reform of enterprises, set up to undertake technology development efforts and effective use of the mechanism, actively explore the effective commercial mode, trying to be a part of the value chain system.

Realize the technology innovation and business model innovation also requires enterprises to actively implement the strategy of innovative personnel training and reserves, attract and keep excellent human resources, some powerful enterprise should try to cooperate with universities, pay more attention to cultivate and attract a group of professional quality and innovation ability of talents. Meanwhile, companies should strive to improve the senior management personnel of innovation consciousness, crisis consciousness and the concept of value chain, and lay a foundation for the long-term development of the enterprise.

\section{Countermeasures for scientific research institution and university}

Scientific research institutes and universities, which provide technology development achievements, should to enhance the consciousness of the transformation of scientific and technological achievements, intensify market-oriented technology development achievements that can provide useful technology results. Institutes and universities should change from only attach importance to technology development itself from the past to emphasize the technical development of the market success, promote the market orientation of technical development activities, make the results of technological development more possible, avoid the embarrassing situation of technology development achievements is limited to articles and samples, which can make the sustained growth of the economy have more reliable technical guarantee.

In order to realize the combination of technology innovation and business model innovation, enterprise needs to make serious exploration and attempt for a long time. The senior managers of enterprise should have crisis awareness to innovative products market value implementation. It also needs enterprises and universities establish long-term cooperation mechanism to in each link of product value chain and the government's policy support. Organic combination of technology innovation and business model innovation model from the exploration to the successful operation is a dynamic process, in which there are many uncertain factors, but once successful, it can create value and exert energy will make the enterprise benefit, each enterprise in the industry through technical innovation and the combination of business model innovation, will eventually increase the industry innovation ability and competitiveness.

\section{CONCLUSION}

In order to promote enterprises to realize the combination of technology innovation and business model innovation, which is to through the establishment of different categories of high-tech park 、 realization of industrial agglomeration a agglomeration of technology and talents, realize the specialization of technology innovation through the high-tech park and agglomeration. Through government advocated to realize effective docking enterprise with high and new technology industrial park, in the application of the system to solve the technology, transformation, and the application of established based on the requirement of the user innovation mechanism, at the same time, the government provides policy support to enterprises to achieve business model innovation, technology innovation and adapt to the business model of organic combination, establish a 
complete smooth value chain, so as to realize the value of appreciation, improve social welfare.

\section{REFERENCES}

[1] Jin Bei,China Industrial Development Report , Economic Management Press:Beijing,pp.103-124,2011

[2] Jin Bei. 60 Years of Experience in China's Industrialization and Inspiration . Qiushi Press. 9(2),pp.56-62,2009

[3] Xu Ning, Xu Xiangyi., The Duality of the Control of the Excitation and the Dynamic Capabilities of the Technological Innovationthe empirical analysis based on high-tech listed company panel data , China's Industrial Economy Press, 10(1),pp.36-52,2011

[4] Qiao Weiguo,Business Model Innovation ,Shanghai Far East Press, Shanghai,pp.65-76,2009.

[5] Hu Baoliang, Business Model Innovation, Technological Innovation and Corporate Performance: the empirical analysis based on high-tech listed company panel data . Technology Progress and Policy Press, 2,pp.89-92,2012

[6] Li Zhiqiang, Zhao Weijun,The Collaborative Research of the Enterprise Technology Innovation and Business Model

[7] Ren Rongwei Lin Xianwo,The Shape and the Meta-analysis of the Heterogeneity of Resources in the New Business in the Early Growth-the Case Study of the Ali Baba's Early Entrepreneurial Growth ,Economic and Management Research Press, 2,pp6569,2008

[8] Yuanlei,Evaluation of the business model theory in foreign countries $[\mathbf{J}\rfloor$ Foreign Economies \& Management 2011, (10)

[9] Afuah, A. , Tueei , C.Internetbusinessmodelsandstrategies: TextandCaseS〔M」.Boston:MeGraw - HillPlrwin, 2012.

[10] TimmersP.Businessmodelsforelectroniemarkets[J].Joumalof EleetronieMarkets, 2011(02)

[11] CharlesB.StabeandYsteinD.Fjeldstad.Configuril:9valueforeomPeti tive advantage:onehainsshoP, and networks.Strategie Managelnent Joumal. 201119, 413 - 37 